\title{
Protocol for a scoping review of the current data practices in forensic medicine
}

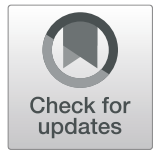

Salona Prahladh ${ }^{1 *}$ and Jacqueline van Wyk $^{2}$

\begin{abstract}
Background: Data related to forensic postmortems or autopsies are still mainly captured in hard copy format and archived. This paper-based practice impacts on the practitioner's ability to report on incidence, prevalence, and statistical trends related to cases that are commonly seen in mortuaries in forensic medicine. An autopsy can be used to inform and provide evidence-based knowledge for further research about important issues, including social development and assist in providing statistics and data for public health initiatives for implementation and monitoring. Currently, in forensic medicine and pathology research developments are largely hampered by the inefficient data capturing system which only allows access to basic information while pertinent information is largely recorded manually and is therefore difficult to obtain. There is thus a need to improve the efficiency of the data capturing system in forensic pathology, and this review is intended to inform the choice and decisions of appropriate data capture practices and is being conducted to identify nationally and internationally the current data mining and storage systems in place.

Methods: The methodology for this scoping review will be guided by the methodological framework for scoping review. The search strategy was developed by the authors, and we will conduct a search from 1 January 2008 of electronic databases (Cochrane Library, Scopus, Web of Science, and Science Direct) and search through WorldCat and PubMed for citations and literature using both keywords and the Medical Subject Headings (MeSH).The electronic search will be supplemented by hand searching references of the included studies and references in journals and websites. All articles will be assessed for eligibility by two reviewers (the primary and secondary authors) and uploaded into EndNote Excel spreadsheet, and duplicates will be identified and removed. The two reviewers (primary and secondary authors) will screen the eligible abstracts and articles against the inclusion criteria, and selection will be on a minimum percentage agreement of 50\%. The selection process will be documented by following and using a PRISMA flow diagram. The extracted data will be analyzed and reported in the form of a narrative review with descriptive analysis and text analysis once the data is summarized for description and characterization.

Discussion: The results of this review will identify and describe data capturing, management, and storage practices for use in forensic medicine. It will also review the efficiency of the different data systems and report where possible on the uses of the data system within the forensic medicine and pathology field.

(Continued on next page)
\end{abstract}

\footnotetext{
* Correspondence: sprahladh@gmail.com

'Department of Forensic Medicine, Inkosi Albert Luthuli Central Hospital, 800

Vusi Mzimela Rd, Umkumbaan, Durban 4091, South Africa

Full list of author information is available at the end of the article
}

(C) The Author(s). 2020 Open Access This article is licensed under a Creative Commons Attribution 4.0 International License, which permits use, sharing, adaptation, distribution and reproduction in any medium or format, as long as you give appropriate credit to the original author(s) and the source, provide a link to the Creative Commons licence, and indicate if changes were made. The images or other third party material in this article are included in the article's Creative Commons licence, unless indicated otherwise in a credit line to the material. If material is not included in the article's Creative Commons licence and your intended use is not permitted by statutory regulation or exceeds the permitted use, you will need to obtain permission directly from the copyright holder. To view a copy of this licence, visit http://creativecommons.org/licenses/by/4.0/. The Creative Commons Public Domain Dedication waiver (http://creativecommons.org/publicdomain/zero/1.0/) applies to the data made available in this article, unless otherwise stated in a credit line to the data. 


\begin{abstract}
(Continued from previous page)
Ethics and dissemination: Although research ethics approval is not required for this scoping review because the study will not include human or animal participants, the study was submitted for approval to the University of Kwazulu Natal Biomedical Research Ethics Committee and obtained provisional approval. Data will be sourced only from published literature and gray literature. The results will be presented at relevant national and international conferences and published in a peer-reviewed journal. All search results including excluded studies will be added into an addendum in the article and made available for public perusal to therefore ensure transparency and reproducibility.
\end{abstract}

Keywords: Autopsy, Postmortem examination, Forensic pathology, Forensic medicine, Data, Database

\section{Background}

The discipline of forensic pathology involves the study of "unnatural" and sudden unexpected deaths. It is a medicolegal investigation process that forms part of the judiciary process, and therefore, consent from relatives is not necessary to perform the autopsy. The medicolegal autopsy is a legal requirement under the Inquests Act, Birth and Deaths Registration Act, Health Professions Act, and Criminal Procedures Act as per the Regulations of Forensic Pathology Services in South Africa [1, 2]. As part of the inquest procedure and the National Code of Guidelines for Forensic Pathology Services, an authorized medical doctor is appointed by the province to perform a postmortem. In South Africa, it is usually a medical professional trained in forensic medicine or a qualified forensic pathologist. But internationally, such as the USA, the coroner and medical examiner system are followed, and the jurisdiction differs in each state $[3,4]$. The medical examiner is an appointed medical practitioner with board certification in medical specialty whereas a coroner is an elected person without professional training. A coroner may refer a case to a medical examiner if needed. Across the world, the death investigation systems may differ in accordance with law.

According to Statistics SA, the report on "Mortality and causes of death in South Africa, 2016: Findings from death notification", the number of deaths were recorded at 456, 612 (11\%), and unnatural deaths were composed of approximately 51,242 (11\%) deaths. One hundred fourteen thousand, four hundred eighty-nine (25\%) postmortem examinations and 44,798 (10\%) autopsies were performed in 2016 [5]. Internationally, although autopsies for external causes of death have increased to approximately $10 \%$, autopsies for hospital-related causes of death declined by $58 \%[6,7]$. This large decline in hospital or clinical autopsies has been mainly attributed to religious reasons and technological advancements which presents a difficult but unique situation to the medical fraternity because autopsy pathology has provided great insight into disease processes and into disease surveillance and progression and therefore has played a large role in medicine to advancement of treatment [8-11].Recently, there has a resurgence in the twenty-first century to focus on patient safety and care, and quality assurance has recently been thrust into the spotlight of late due to patients being more informed and educated, human nature being generally inquisitive, and the widespread accessibility of information on the internet. Medical malpractice and misdiagnosis claims have seen a steady increase over the last decade [12]. Improving our current reporting system on medicolegal autopsies can be used to fill in the gaps in autopsy pathology, identify issues of high importance, and retrain medical personnel appropriately and will ultimately improve the quality of patient care which are important aspects of public health and health care in general. Postmortems provide important and underutilized information that are inaccessible if not captured appropriately. Internationally, it has been shown that secondary use of clinical data can be accelerated by modernizing our current health care infrastructure with regard to health records [13-16]. But currently, research is laborious and difficult, due to the unavailability of data which is only accessible presently manually or in hard copy format at each mortuary. The collection, storage, and dissemination of important health care information for use in academic departments and governmental organizations have advantages for public health such as epidemiology studies, health surveillance and to institute appropriate preventative measures [1720]. Therefore, improving and streamlining data management in medicine are important to provide an intuitive system with appropriate tools to support new and ongoing projects [6]. While paper records are essential, the advancement of technology allows for data to be entered into a computerized database that can further be compared and analyzed, thereby greatly reducing laborious efforts of accessing paper-based information and increasing the utility of the information for teaching, research, epidemiology, and health monitoring. Medical data proves to be unique in a lot of aspects including heterogeneity, data types, confidential storage of privacy sensitive voluminous health records, and transmission of the information for ancillary use, and therefore, appropriate and adequate 
recording systems are a prerequisite [21-23]. There is a need to improve current data reporting systems in place to support forensic medicine as well as medicine [24, 25]. The objective of this scoping review is to gain insight on the different data capturing systems and how it has impacted on different departments in medicine with a special interest in forensic medicine and data capturing in autopsy reporting.

\section{Methodology}

This scoping review will be conducted to gather evidence from the literature on the use, benefits, and application of electronic data information practices in forensic medicine and will be extended to similar academic health-related disciplines. The objectives are to identify and review current data practices for collection, storage, and management of health care records; examine the literature on the different methods used; explore and describe literature relating to the impact of current; and improve data collection and management practices in forensic pathology and medicine. It is anticipated that the results of this study will inform the medical fraternity, the public, and the government of the importance of good and efficient data capturing methods in health care advancement and inform on decisions relating to implementing such systems in the forensic medicine department.

\section{Scoping review}

We will conduct a systematic scoping review of literature reporting on at least the last 10 years in data capturing practices and database management in forensic medicine and pathology locally and internationally and in healthrelated disciplines. A scoping review method was selected as a method to outline different types of evidence on the area of interest and to fill in the gaps for further research. The proposed review will be guided by the methodological frameworks proposed by Arksey and o'Malley and from the Joanna Briggs Institute Tricco et al. [26-29]. Thus, the following five steps will be followed in this scoping review: (i) identifying the research question, (ii) identifying relevant studies, (iii) selection of eligible studies, (iv) charting the data, and (v) collating and summarizing the results. Quality appraisal of studies will not be conducted as this review aims to explore the general scope of research conducted in this field.

\section{Identifying the research question}

The main research question is "What are the data capturing and storage methods in forensic medicine and pathology?"

The research sub-questions are as follows:
- What data recording and reporting methods are used in forensic medicine and pathology internationally?

- What are the data recording and reporting methods used in forensic medicine and pathology locally (in the South African context?)

- What are the documented and/or reported impact of improved data recording and reporting on training, research, and the ability to provide national/provincial statistics?

- What is the value of data management systems in medicine and in health reporting or other uses/ benefits reported?

This study will use the PRISMA framework (Fig. 1) to align study selection with the research question and will follow the relevant aspects of the Preferred Reporting Items for Systematics Review and Meta-Analysis Protocols (PRISMA-P) extension for scoping reviews guidelines (Table 1) to ensure thorough reporting and mapping of the body of literature [31].

\section{Identifying relevant studies}

A search will be conducted for published and gray literature on the research area from January 2008. The search strategy has been included in a separate file as an addendum. The searches will be limited to articles in English and published from 2008. A hand or manual search will be conducted of the references of the included studies and websites such as the World Health Organization (WHO) and Department of Health (Provincial, National, and International). We will also examine reference lists for additional relevant articles (searching manually).

The results will be reviewed by the research team to ensure validity of the search strategy. The research team (primary and secondary author) will reach a percentage agreement of at least $50 \%$ on the included studies (Due to the complex and specialized area of field, the research is being conducted on the primary and secondary author will have to reach the percentage agreement for the study to be included. If not, the study will be excluded with reasons given from the team). Results from each database search, and from manual searches, will be exported to a single library in the EndNote X9 software (Thomson Reuters, 2016). Duplicate studies will be identified and removed using the EndNote program. The electronic database search will be recorded in a table (Table 2).

\section{Selection of eligible studies}

Title and abstract screening will be guided by the PRISMA framework (Tables 2 and 3) [31]. Application of further eligibility criteria will ensure that the content of the included studies is relevant to the aim of the study 
PRISMA 2009 Flow Diagram

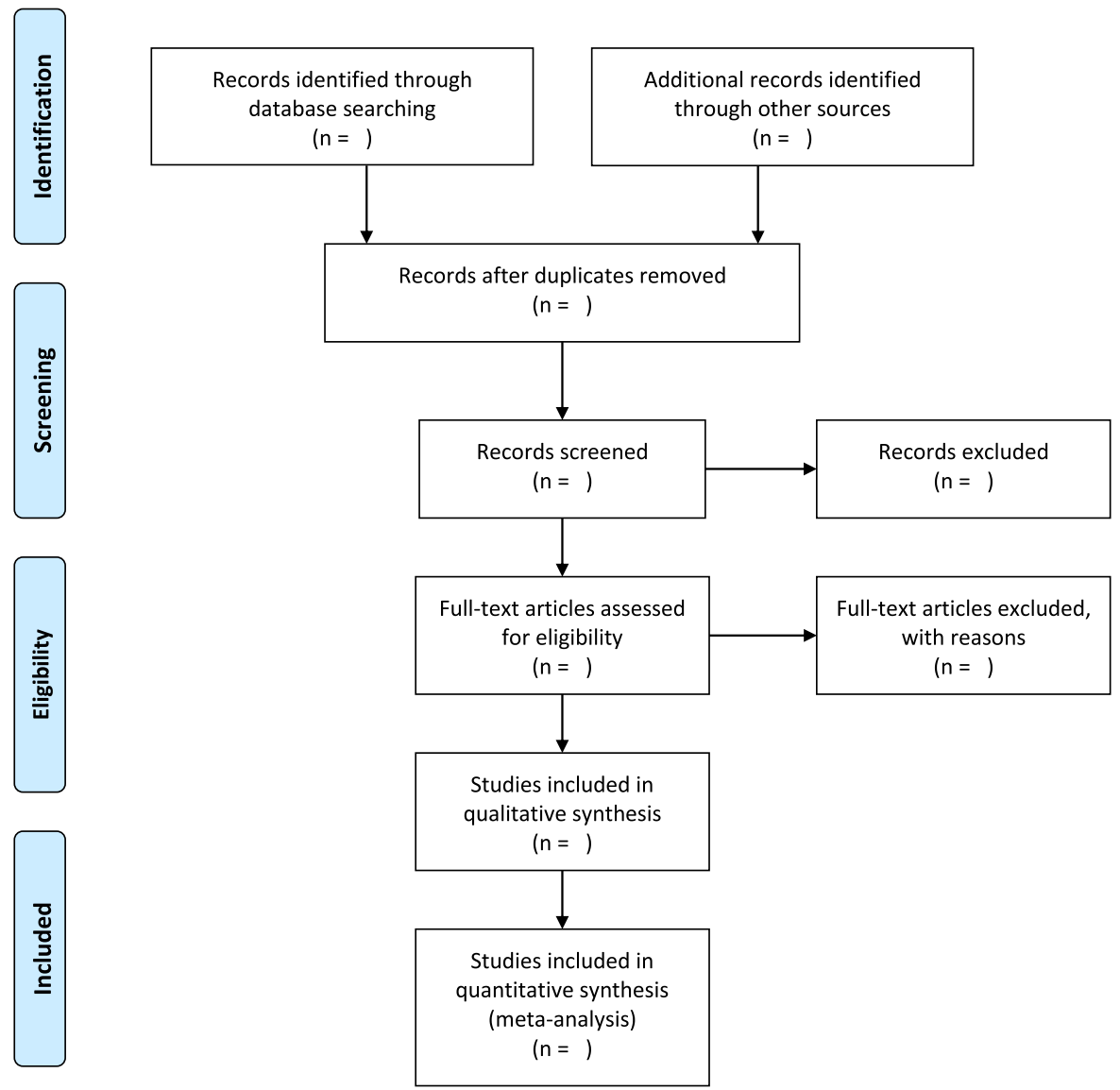

Fig. 1 PRISMA 2009 flow diagram. From [30] Moher D et.al

and the research question. The articles will be assessed for relevance and will be inclusive of all types of literature including review articles, commentary articles, editorials, abstracts from conferences, and other studies including empirical studies with all types of methodology (quantitative, qualitative, mixed, etc.).

\section{Inclusion criteria}

For studies to be included, they must meet the following criteria:

- Articles on medical data capturing

- Articles on data capturing of unnatural deaths, autopsies/postmortem examinations, or forensic medicine and pathology

- Conducted internationally or nationally

- Report on current data selection/management practices and the impact of the systems

- Published from 1 January 2008 until current
- Primary qualitative and quantitative studies and abstracts from conferences will be included.

- Available in English

\section{Exclusion criteria}

Studies will be excluded if they have any of the following characteristics:

- Data collection and management practices not relating to medicine

- Studies focusing only on case reporting

- Studies where full text article could not be obtained

The two reviewers (primary and secondary authors) will use the inclusion criteria to determine eligibility of the selected and identified studies for the review and will subsequently conduct article and full-text screening of all eligible articles. Articles will be selected on a minimum agreement of at least $50 \%$ between the two 
Table 1 Preferred Reporting Items for Systematics Review and Meta-Analysis Protocols (PRISMA-P) extension for scoping reviews guidelines

\begin{tabular}{|c|c|c|c|}
\hline SECTION & ITEM & PRISMA-ScR CHECKLIST ITEM & $\begin{array}{l}\text { REPORTED } \\
\text { ON PAGE\# }\end{array}$ \\
\hline \multicolumn{4}{|l|}{ TITLE } \\
\hline Title & 1 & Identify the report as a scoping review. & 4 \\
\hline \multicolumn{4}{|l|}{ ABSTRACT } \\
\hline $\begin{array}{l}\text { Structured } \\
\text { summary }\end{array}$ & 2 & $\begin{array}{l}\text { Provide a structured summary that includes (as } \\
\text { applicable): background, objectives, eligibility criteria, } \\
\text { sources of evidence, charting methods, results, and } \\
\text { conclusions that relate to the review questions and } \\
\text { objectives. }\end{array}$ & $2-3$ \\
\hline \multicolumn{4}{|l|}{ INTRODUCTION } \\
\hline Rationale & 3 & $\begin{array}{l}\text { Describe the rationale for the review in the context of } \\
\text { what is already known. Explain why the review } \\
\text { questions/objectives lend themselves to a scoping } \\
\text { review approach. }\end{array}$ & 7 \\
\hline Objectives & 4 & $\begin{array}{l}\text { Provide an explicit statement of the questions and } \\
\text { objectives be ing addressed with reference to their key } \\
\text { elements (e.g., population or participants, concepts, and } \\
\text { context) or other re levant key elements used to } \\
\text { conceptualize the review questions and/or objectives. }\end{array}$ & 8 \\
\hline \multicolumn{4}{|c|}{ 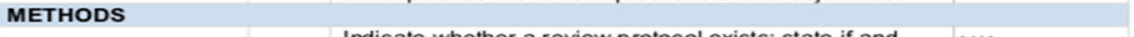 } \\
\hline $\begin{array}{l}\text { Protocol and } \\
\text { registration }\end{array}$ & 5 & $\begin{array}{l}\text { Indicate whether a review protocol exists; state if and } \\
\text { where it can be accessed (e.g., a Web address); and if } \\
\text { available, provide registration information, including the } \\
\text { registration number. }\end{array}$ & N/A \\
\hline Eligibility criteria & 6 & $\begin{array}{l}\text { Specify characteristics of the sources of evidence used } \\
\text { as eligibility criteria (e.g., years considered, language, } \\
\text { and publication status), and provide a rationale. }\end{array}$ & 12 \\
\hline $\begin{array}{l}\text { Information } \\
\text { sources* }\end{array}$ & 7 & $\begin{array}{l}\text { Describe all information sources in the search (e.g., } \\
\text { databases with dates of coverage and contact with } \\
\text { authors to identify additional sources), as well as the } \\
\text { date the most recent search was executed. }\end{array}$ & $\begin{array}{l}6 \text { and } \\
\text { additional file }\end{array}$ \\
\hline Search & 8 & $\begin{array}{l}\text { Present the full electronic search strategy for at least } 1 \\
\text { database, including any limits used, such that it could be } \\
\text { repeated. }\end{array}$ & additional file \\
\hline $\begin{array}{l}\text { Selection of } \\
\text { sources of } \\
\text { evidencet }\end{array}$ & 9 & $\begin{array}{l}\text { State the process for selecting sources of evidence (i.e., } \\
\text { screening and eligibility) included in the scoping review. }\end{array}$ & 6-13 \\
\hline $\begin{array}{l}\text { Data charting } \\
\text { process } \ddagger\end{array}$ & 10 & $\begin{array}{l}\text { Describe the methods of charting data from the included } \\
\text { sources of evidence (e.g., calibrated forms or forms that } \\
\text { have been tested by the team before their use, and } \\
\text { whether data charting was done independently or in } \\
\text { duplicate) and any processes for obtaining and } \\
\text { confirming data from investigators. }\end{array}$ & 14 \\
\hline Data items & 11 & $\begin{array}{l}\text { List and define all variables for which data were sought } \\
\text { and any assumptions and simplifications made. }\end{array}$ & 14 \\
\hline $\begin{array}{l}\text { Critical appraisal of } \\
\text { individual sources } \\
\text { of evidence }\end{array}$ & 12 & $\begin{array}{l}\text { If done, provide a rationale for conducting a critical } \\
\text { appraisal of included sources of evidence; describe the } \\
\text { methods used and how this information was used in any } \\
\text { data synthesis (if appropriate). }\end{array}$ & 13 \\
\hline Synthesis of results & 13 & $\begin{array}{l}\text { Describe the methods of handling and summarizing the } \\
\text { data that were charted. }\end{array}$ & $13-15$ \\
\hline SECTION & ITEM & PRISMA-SCR CHEGKLIST ITEM & $\begin{array}{l}\text { REPORTED } \\
\text { ONPAGE\# }\end{array}$ \\
\hline \multicolumn{4}{|c|}{ Give numbers of sources of evidence screened. } \\
\hline $\begin{array}{l}\text { Selection of } \\
\text { sources of } \\
\text { evidence }\end{array}$ & 14 & $\begin{array}{l}\text { Give numbers of sources of evidence screened, } \\
\text { assessed for eligibility, and included in the review, with } \\
\text { reasons for exclusions at each stage, ideally using a flow } \\
\text { diagram. }\end{array}$ & N/A Protocol \\
\hline $\begin{array}{l}\text { Characteristics of } \\
\text { sources of } \\
\text { evidence }\end{array}$ & 15 & $\begin{array}{l}\text { For each source of evidence, present characteristics for } \\
\text { which data were charted and provide the citations. }\end{array}$ & N/A Protocol \\
\hline $\begin{array}{l}\text { Critical appraisal } \\
\text { within sources of } \\
\text { evidence }\end{array}$ & 16 & $\begin{array}{l}\text { If done, present data on critical appraisal of included } \\
\text { sources of evidence (see item 12). }\end{array}$ & N/A scoping rev \\
\hline $\begin{array}{l}\text { Results of } \\
\text { individual sources } \\
\text { of evidence }\end{array}$ & 17 & $\begin{array}{l}\text { For each included source of evidence, present the } \\
\text { relevant data that were charted that relate to the review } \\
\text { questions and objectives. }\end{array}$ & N/A \\
\hline \multicolumn{3}{|r|}{$\begin{array}{l}\text { relate to the review questions and objectives. } \\
\text { Summarize the main results (including an overview of }\end{array}$} & \\
\hline $\begin{array}{l}\text { Summary of } \\
\text { evidence }\end{array}$ & 19 & $\begin{array}{l}\text { Summarize the main results (including an overview of } \\
\text { concepts, themes, and typess of evidence available), link } \\
\text { to the review questions and objectives, and consider the } \\
\text { relevance to key groups. }\end{array}$ & 16 \\
\hline Limitations & 20 & $\begin{array}{l}\text { Discuss the limitations of the scoping review process. } \\
\text { Provide a general interpretation of the results with }\end{array}$ & 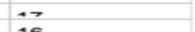 \\
\hline $\begin{array}{l}\text { Conclusions } \\
\text { FUNDING }\end{array}$ & 21 & $\begin{array}{l}\text { respect to the review questions and objectives. as well } \\
\text { as potential implications and/or next steps. }\end{array}$ & 16 \\
\hline \multicolumn{2}{|c|}{$\begin{array}{l}\text { as potential implications and/or next steps. } \\
\text { Describe sources of funding for the included sources of }\end{array}$} & Describe sources of funding for the included sources of & \\
\hline Funding & 22 & $\begin{array}{l}\text { evidence, as well as sources of funding for the scoping } \\
\text { review. Describe the role of the funders of the scoping } \\
\text { review. }\end{array}$ & 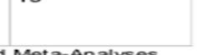 \\
\hline \multicolumn{4}{|c|}{ 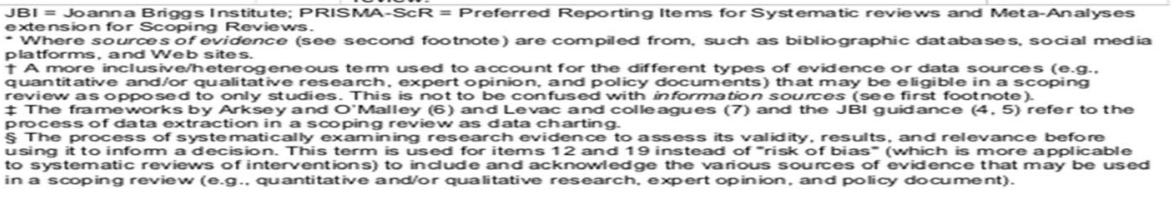 } \\
\hline
\end{tabular}


Table 2 Electronic Database Search Recording Table

\begin{tabular}{lllll}
\hline $\begin{array}{l}\text { Date of } \\
\text { search }\end{array}$ & $\begin{array}{l}\text { Electronic } \\
\text { database }\end{array}$ & $\begin{array}{l}\text { Keywords } \\
\text { searched }\end{array}$ & $\begin{array}{l}\text { Number of } \\
\text { studies retrieved }\end{array}$ & $\begin{array}{l}\text { Number of } \\
\text { studies selected }\end{array}$ \\
\hline
\end{tabular}

reviewers due to the complex and specialized field the review will entail (data management in forensic medicine/medicine related to autopsy reporting). An agreement will be reached after discussion until a consensus is reached. Bibliographic details, study design, intervention, comparison, study setting, funding sources, and conclusions are some of the data information that will be extracted. All attempts will be made to obtain fulltext copies of selected articles, by engaging with the University of Kwazulu Natal librarian or contacting the author if necessary via email and via the University of Kwazulu Natal library.

The selection process will follow the recommendations in the Preferred Reporting Items for Systematic Reviews and Meta-Analyses Extension for Scoping Reviews (PRISMA-ScR) checklist [25] and be mapped using the PRISMA-P chart and the percentage agreement between the two reviewers.

Table 3 Data charting form

\begin{tabular}{|c|c|}
\hline Data chart heading & Description \\
\hline Author & Name of author/s \\
\hline Date & Date article sourced \\
\hline Title of study & Title of the article or study \\
\hline Publication year & Year that the article was published \\
\hline Publication type & Journal, website, conference, etc. \\
\hline $\begin{array}{l}\text { Study details and design (if } \\
\text { applicable) }\end{array}$ & Type of study, empirical or review, etc. \\
\hline Keywords & What key words were present \\
\hline Abstract screening & Screening for appropriateness of article \\
\hline Study sector/setting & Country/state/hospital/mortuary \\
\hline Study population & $\begin{array}{l}\text { Population studied with regard to } \\
\text { demographics }\end{array}$ \\
\hline Number of reviewers & Number of reviewers reviewing article \\
\hline $\begin{array}{l}\text { Types of data sources } \\
\text { included }\end{array}$ & Detail the data sources \\
\hline Reported impact or benefits & $\begin{array}{l}\text { List the impact reported, intervention, } \\
\text { comparison }\end{array}$ \\
\hline $\begin{array}{l}\text { Reported challenges or } \\
\text { limitations }\end{array}$ & What challenges were encountered \\
\hline Conclusion & Important aspects of the conclusion \\
\hline Most significant findings & Noteworthy results of the study \\
\hline Most relevant findings & $\begin{array}{l}\text { Findings that contribute to the research } \\
\text { question }\end{array}$ \\
\hline
\end{tabular}

\section{Charting the data}

A data charting form will be used to electronically capture relevant information from each included study. The extracted data will include the following fields (Table 3).

\section{Collating, summarizing, and reporting the results}

A narrative report will be produced to summarize the extracted data around the following outcomes: efficiency of data capturing and database systems; utility of data systems; and impact on research, statistics, and training. These results will be described in relation to the research question and in the context of the overall study purpose. Gap identification will detect areas, such as countries that lack research on proper data capturing practices and paucity of data on data capturing.

\section{Discussion}

This scoping review aims to identify and describe the databases use and value in the department of forensic medicine and the benefits of its use to be available for department development, epidemiological research, statistics, health trends, social development public interventions, and research.

Electronic data capturing has the potential to greatly reduce the time and costs associated with data collection. Internationally, primary health care databases are used to provide anonymized electronic health data that is utilized for research that serve both observational and interventional purposes [32, 33]. The development of software and tools to improve recording systems to support practitioners and other groups involved in health care advancement has been on a steady rise [34, 35]. In the Western Cape of South Africa Forensic Pathology Services, an excel spread system is utilized to save data and information from autopsies. In 1975, the College of American Pathologists developed a computerized $\mathrm{Na}$ tional Autopsy Databank to serve as a source of pathological, biomedical, demographic, and epidemiological information to benefit research [31, 32]. It has shown how this has greatly increased research output. In the current technological age, this is now possible and realistic to create an accessible repository of records stored in an electronic format.

The database developed by Drs. Moore, Berman, and Hutchins consists of over 49,000 autopsy fact sheets contributed by numerous academic medical institutions. To date, 1200 research papers have been published using the records from that database. An autopsy database that contains information of value for epidemiologists and other researchers is technically feasible using current technology and can be designed to protect patient privacy $[22,23,36,37]$. Placing the autopsy database on the computer maximizes its access to researchers interested in using or contributing to the database also thus 
improving standards $[24,25]$. This review is the first part of a study to develop guidelines for efficient data capturing practices in forensic medicine which has not been reported on previously according to the authors' knowledge. The results of this review will provide an understanding of the international and other provincial databases and their utility which will assist in developing new methods of data management in medicine. This review also has the potential to create greater awareness of how postmortem information can be used to develop and promote scientific studies to establish new medical information for use in teaching, statistics reporting, and trauma and injury progression process to improve patient care and for promotion of public health and safety. It is an important topic to support the transition to efficient reporting in the forensic medicine department and is envisioned to provide a platform that can be used in other medical departments.

\section{Limitations}

Currently, only data reporting and management practices used in forensic medicine, in medicine, or in autopsies will be used. This may exclude studies in other departments.The keywords to be used in the search strategy are broad and may not identify specialized studies in data management. Only articles in English will be used.

\section{Authors' contributions}

SP conceptualized the study and prepared the draft protocol under the supervision of JVW. Both SP and JVW contributed to the development of the background, design of the study, and planned output of the research. SP prepared the manuscript, and JVW reviewed it. The authors read and approved the final manuscript.

\section{Funding}

Nil.

\section{Availability of data and materials}

All data generated or analyzed during this study will be included in the published scoping review article. This will include all search results, list of excluded studies, spreadsheets, and data used for the meta-analyses, and reasons for why the selected studies were included will also be published in the article. This will ensure transparency and reproducibility.

\section{Ethics approval and consent to participate}

Although research ethics approval is not required for this scoping review because the study will not include human or animal participants, the study was submitted for approval to the University of Kwazulu Natal Biomedical Research Ethics Committee, and provisional approval was received. Data will be sourced only from published literature and gray literature.

\section{Consent for publication}

Not applicable.

\section{Competing interests}

The authors declare they have no competing interests.

\section{Author details}

${ }^{1}$ Department of Forensic Medicine, Inkosi Albert Luthuli Central Hospital, 800 Vusi Mzimela Rd, Umkumbaan, Durban 4091, South Africa. ${ }^{2}$ Discipline of Clinical and Professional Practice, College of Health Sciences, University of KwaZulu-Natal, Durban, South Africa.
Received: 30 September 2019 Accepted: 23 February 2020

Published online: 08 April 2020

\section{References}

1. Government of the Republic of South Africa. Regulations regarding the rendering of forensic pathology services https://www.polity.org.za/ attachment.php?aa_id=738552003. [updated 2018; cited 201930 March 2019].

2. Government of the Republic of South Africa. Government acts, https:// www.gov.za/documents/acts 2019. [cited 20 March 2019].

3. Tae M, Choo YSC, Lee H, Seo JS. Medicolegal death investigation system in America. Korean J Legal Med. 2012;36:135-43 Epub November 2012.

4. Committee for the Workshop of the Medicolegal Death Investigation System. Medicolegal death investigation system: workshop summary. National Academy of Sciences: National Academy of Sciences; 2003.

5. Statistics South Africa. Mortality and causes of death in South Africa, 2016: findings from death notification http://www.statssa.gov.za/publications/P03 093/P030932016.pdf: Statistics South Africa; 2016 [cited 20 April 2019].

6. Hovert D. The changing profile of autopsied deaths in the United States. NCHS Data Brief. 2011;67:1-8. Epub August 2011.

7. Canada S. Canadian coroner and medical examiner database: annual report 2006 to 2008.

8. Bagher a JWb, c, A. Ottosson b,c, L. Andersson d, S. Wangefjord a, S. Acosta. Necessity of including medico-legal autopsy data in epidemiological surveys of individuals with major trauma. Int J Care Injured. 2015 (46).CM Reichert VK.

9. Prognosis for the autopsy. KellyHealthAffairsorg. 1985;4(2):82-92.

10. Feng HXY, Mao Z, Zhang W, et al. An analysis of 60 years of autopsy data from Zhejiang University in Hangzhou. China J Pone. 2014.

11. Jan H F. Remme TA, Francisco Becerra-Posada, Catherine D'Arcangues, Michael Devlin, Charles Gardner, Abdul Ghaffar, Joachim Hombach, Jane F. K. Kengeya, Anthony Mbewu, Michael T. Mbizvo, Zafar Mirza, Tikki Pang, Robert G. Ridley, Fabio Zick, Robert F Terry. Defining research to improve health systems. PLoS Medicine | www.plosmedicine.org. 2010;7(1):1-7. Epub November 162010.

12. Madea B. Medicolegal autopsies as a source of information to improve patient safety. Legal Medicine. 2009. https://doi.org/10.1016/j.legalmed.2009. 01.108 .

13. Anita de Waard DHC. 10 aspects of highly effective research data. elseviercom/connect.

14. Joshua D. Franklin AG, James F. Brinkley. A partnership approach for electronic data capture in small-scale clinical trials. J Biomed Informat. 2011.

15. Ioana Danciu JDC, Basford M, Wang X, Saip A, Osgood S, Shirey-Rice J, Kirby J. Harris PA. Secondary use of clinical data: the Vanderbilt approach. J Biomed Informat. 2014;52:28-35 Epub December 2014.

16. Jones S. Bringing it all together: a case study on the improvement of research data management at Monash University. http://www. researchdatamonash.edu.au/guidelines/planning.html.

17. J Murray JD, Jl Phillips, Routinely collected laboratory data: a neglected resource, 2012, Medical Technology SA, www.smltsa.org.za, Vol 26 No.1. Medical Technology SA, www.smltsa.org.za. 2012;26(1):5-8. Epub June 2012.

18. Tim Williams TS, Puri S, Eaton S. Recent advances in the utility and use of the General Practice Research Database as an example of a UK Primary Care Data resource. Ther Adv Drug Saf. 2012;3(2):88-99.

19. Eran Bellin DDF, Geberer N, Islam S, Srivastava N. Democratizing information creation from health care data for quality improvement, research, and education - the Montefiore Medical Center experience. MBA Academic Medicine.

20. Emily Herrett AG. Data resource profile: clinical practice research datalink. Int J Epidemiol. 2015;44(3).

21. Baker TGR. The contribution of case study research to knowledge of how to improve quality of care. BMJ Qual Saf. 2011.

22. Krzysztof J. Cios GWM. Uniqueness of medical data mining. Artificial Intelligence in Medicine. 2002;26:1-24. Epub March 2002.

23. gpnetwork@cprd.com. Safeguarding patient data. https://www.cprd.com/ safeguarding-data.

24. Diane Kelsall, MJB. No standards: medicolegal investigation of deaths. CMAJ 2016.

25. Levy B. The need for informatics to support forensic pathology and death investigation. J Pathol Inform. 2015;6(32).

26. Arksey HOML. Scoping studies: towards a methodological framework. Int J Soc Res Methodol. 2005;8(1):19-32. 
27. LE Tricco AC, Zarin W, O'Brien KK, Colquhoun H, Levac D, et al. PRISMA extension for scoping reviews (PRISMA-ScR): checklist and explanation. Ann Intern Med. 2018;169(7):467-73.

28. Peters MDGC, Khalil H, Mclnerney P, Parker D, Soares CB. Guidance for conducting systematic scoping reviews. Int J Evid Based Healthc. 2015;13(3): 141-6.

29. Moher DSL, Clarke M, Ghersi D, Liberati A, Petticrew M, et al. Preferred reporting items for systematic review and meta-analysis protocols (PRISMAP) 2015 statement. Syst Rev. 2015;4(1).

30. Moher D, Liberati A, Tetzlaff J, Altman DG, The PRISMA Group (2009). Preferred Reporting Items for Systematic Reviews and Meta-Analyses: the PRISMA statement. PLoS Med 6(7): e1000097. https://doi.org/10.1371/journal. pmed1000097.

31. Alessandro Liberati DGA, Jennifer Tetzlaff, Cynthia Mulrow et al. The PRISMA statement for Reporting Systematic Reviews and Meta-Analyses of studies that evaluate health care interventions: explaination and elaboration. BMJ www.bmj.com. 2009;6(7):1-28.

32. Moore GWBJ, Hanzlick RL, Buchino JJ, Hutchins GM. A prototype international autopsy database: 1625 consecutive fetal and neonatal autopsy facesheets spanning twenty years. Archives Pathol Lab Med. 1996; 120(8):782-5.

33. Jules J. Berman GWM, Grover M Hutchins,. Maintaining patient confidentiality in the public domain internet autopsy database. PMC. 1996: 328-332.

34. Abraham D. Flaxman LH, Jonathan Joseph, Jonathan Brown, Christopher J.L. Murray. A de-identified database of 11,979 verbal autopsy open-ended responses. 2018

35. Abraham D, Flaxman AS, Jonathan C, Joseph NA, Alam SS, Chowdhury H, Mooney MD, Rampatige R, Remolador H, Sanvictores D, Serina PT, Streatfield PK, Tallo V, Murray CJL, Hernandez B, Lopez AD, Flaxman IDR. Collecting verbal autopsies: improving and streamlining data collection processes using electronic tablets. Population Health Metrics. 2018.

36. Alves AL, Pedro \& Oliveira, Pedro \& Ferreira, Marco \& Sousa Pinto, Catia. Standardized autopsy report and online death certificate in Portugal - a joint collaboration of the College of Pathology and the Directorate-General of Health (DGS). Modern Pathology. 2015.

37. Emin Aghayev LS, Richard Dirnhofer, Tony Ambrose, Christian Jackowski, Kathrin Yen, Stephan Bolliger, Andreas Christe, Christoph Roeder,Max Aebi, Michael J. Thali Virtopsy - the concept of a centralized database in forensic medicine for analysis and comparison of radiological and autopsy data. J Forensic Legal Med 2008:135-140.

\section{Publisher's Note}

Springer Nature remains neutral with regard to jurisdictional claims in published maps and institutional affiliations.

Ready to submit your research? Choose BMC and benefit from:

- fast, convenient online submission

- thorough peer review by experienced researchers in your field

- rapid publication on acceptance

- support for research data, including large and complex data types

- gold Open Access which fosters wider collaboration and increased citations

- maximum visibility for your research: over $100 \mathrm{M}$ website views per year

At $\mathrm{BMC}$, research is always in progress.

Learn more biomedcentral.com/submissions 